\title{
Real-time monitoring of local scour by using fiber Bragg grating sensors
}

\author{
Yung-Bin Lin ${ }^{1}$, Jin-Chong Chen ${ }^{2}$, Kuo-Chun Chang ${ }^{2}$, \\ Jenn-Chuan Chern ${ }^{2}$ and Jihn-Sung Lai ${ }^{3}$ \\ ${ }^{1}$ National Center for Research on Earthquake Engineering, 200, Section 3, Hsinhai Road, \\ Taipei 106, Taiwan \\ 2 Department of Civil Engineering, National Taiwan University, Taipei 106, Taiwan \\ ${ }^{3}$ Hydrotech Research Institute, National Taiwan University, 158 Chow-Shan Road, Taipei \\ 106, Taiwan
}

E-mail: yblin@ncree.gov.tw,jingochen@ntu.edu.tw,ciekuo@ntu.edu.tw, jcchern@ntu.edu.twand jslai@hy.ntu.edu.tw

Received 17 February 2004, in final form 3 December 2004

Published 15 June 2005

Online at stacks.iop.org/SMS/14/664

\begin{abstract}
Local scour is one of the major factors for bridge failure. Scour failures tend to occur suddenly and without prior warning or sign of distress to the structure. Two types of real-time monitoring systems for bridge scour, using fiber Bragg grating (FBG) sensors, have been developed and tested in the laboratory. These FBG scour-monitoring systems can measure both the processes of scouring/deposition and the variations of water level. Several experimental runs have been conducted in the flume to demonstrate the applicability of the FBG systems. The experimental results indicate that the real-time monitoring system has the potential for further applications in the field.
\end{abstract}

(Some figures in this article are in colour only in the electronic version)

\section{Introduction}

It is well known that scour is one of the major causes for bridge failure [1-16]. When scouring occurs, the bed materials around the pier footing can be eroded, leaving the infrastructure such as the bridge piers and abutments in an unsafe condition, and in danger of collapse with the distinct possibility of loss of life. More than 1000 bridges have collapsed over the past 30 years in the USA, with $60 \%$ of the failures being due to scour [1]. This serious problem also happens in many EastAsian countries such as Taiwan, Japan, Korea, owing to the fact that these areas are subject to several typhoon and flood events each year during the summer and fall seasons. Scour failure tends to occur suddenly and without prior warning or sign of distress to the structures. The nature of the failure is usually defined as the complete collapse of an entire section of a bridge. There were 68 bridges damaged due to scour damage in Taiwan, based on a survey from 1996 to 2001 [2]. Scouring at a bridge pier in the river can be caused by general scour, contraction scour or local scour. Among them, local scour is the most critical; it is generally caused by the interference of the structures with river flow, and it is characterized by the formation of a scour hole at bridge piers or abutments. A great deal of time, money and effort has been dedicated to the development and evaluation of scour detection and instrumentation in order to obtain more accurate measurements. However, it is not easy to measure or monitor the depth variations of scouring at piers, especially in a flood.

Many methodologies and instruments have been proposed for measuring and monitoring, such as sonar, radar, and timedomain reflectometry (TDR) to estimate or predict the local scour depth at bridge foundations [3-16]. However, most of these available techniques have limited applications. For example, both sonar and radar are easy to install, but the results are difficult to interpret, especially when the running water contains high concentration sediments, debris or rocks in a flooded river. In addition, the noise caused by the turbidity of the flow will make those systems unreliable for real-time monitoring of the scouring processes. Therefore, radar and sonar are usually good for applications after flood, and the 
data of scour depth measured can mainly indicate the final status of the degradation/aggregation surrounding the bridge pier [3-6]. However, instead of the final scour depth after flood, the actual deepest scour depth (i.e. maximum scour depth during flood) is much more important to the safety of the bridge structure; this generally occurs near the peak flood discharge. The TDR technique is operated by generating an electromagnetic pulse and coupling it to a transmission line or cable [7-9]. The response signal changes if there is any variation in the current or potential. Since the cable as a transmission line is often several hundreds of meters in length, the pulse attenuates and disperses the TDR signal. This drawback reduces the ability to detect subtle scour changes. In addition, the electromagnetic environment also affects the accuracy of the results. A piezoelectric sensor, consisting of a series of spatially separated piezo films, provides incrementalspatial resolution to track the entire scour cycle $[10,11]$. However, this is a delicate set-up and it is susceptible to being damaged by muddy waters and debris in the flooding period.

Therefore, a local scour depth monitoring system faces the challenge of developing a real-time, reliable and robust system, which can be installed in a river bed near the bridge pier or abutment. Moreover, it is well known that the established scour formula for estimating the maximum scour depth relates to the characteristics, including the flow depth, velocity and sediment size. In practice, the limitations of the scour formula should be addressed before one can apply it adequately. The recognition of any possible aggradation and degradation of the river-bed level in response to a channel disturbance is important for the prediction of channel bed variations. In addition, the scour process around the pier or abutment is essentially complex due to the three-dimensional flow patterns interacting with sediments. However, most of the data obtained to develop the scour formula are collected from the laboratory instead of from the field. Thus, it is necessary to develop a real-time system for monitoring and measuring the scour depth in the field.

In the present study, two novel FBG monitoring systems are developed and used in the real-time measurement of the process of local scour. Applying the FBG sensor systems, the laboratory data of the water level, scour depth and deposition height are collected and analyzed herein.

\section{Fiber Bragg grating sensor}

An optical fiber sensory system, specifically fiber Bragg grating (FBG) sensors, has been developed and proven to have excellent long-term stability and a high reliability in strain and temperature measurements [17-23]. In order to fulfill the monitoring needs of a large structure, an optical fiber sensory system can provide many sensor locations together with minimum processing requirements. Civil structures must resist environmental and in-service loads such as wind, earthquake, traffic, and thermal effects. It has been demonstrated that an intelligent sensory system coping with optical fiber sensors is highly effective in monitoring the dynamic responses of structures under the above-mentioned external loads.

Current technology allows the FBG sensors to be easily fabricated and placed in materials through a side exposure technique. Two typical configurations consist of either exposing a small portion of the optical fiber to two interfering beams of ultraviolet (UV) light or having one UV beam focused through a phase mask. This creates a periodic modulation of the refractive index in the core of an optical fiber. Due to the periodic nature of the index perturbation, only certain discrete optical frequencies will resonate in the structure. Therefore, if broadband light is traveling in the core of the optical fiber, the incident energy at such a resonant frequency will be reflected back down the optical fiber.

It is known that the Bragg phase-matching condition [17-23] determines the Bragg wavelength, $\lambda_{B}$, of a fiber grating. The wavelength shift $\Delta \lambda_{B}$ of an FBG sensor, subject to physical disturbance, can be expressed as:

$$
\frac{\Delta \lambda_{\mathrm{B}}}{\lambda_{\mathrm{B}}}=\left(1-p_{\mathrm{e}}\right) \varepsilon+(\alpha+\xi) \Delta T
$$

in which $P_{\mathrm{e}}, \varepsilon, \alpha, \xi$, and $\Delta T$ are the effective photoelastic constant, axial strain, thermal expansion coefficient, thermal optic coefficient and temperature shift, respectively. These coefficients generally depend on the type of optical fibers used and the wavelengths at which they are written and measured. However, in sensor applications, the wavelength shifts induced by variations of the doped materials in the optical fiber can be treated as constants, as compared to those induced by structural strain, because measurements of the fractional Bragg wavelength variations, induced by the doped materials, are small. As can be seen in equation (1), any change in the periodicity of the refractive index modulation or the overall index of refraction will change the Bragg wavelength. Consequently, any temperature or strain-induced effect on the FBG can be determined by a corresponding shift in the center Bragg wavelength.

In the other words, the shift of the Bragg wavelength, $\Delta \lambda$, can be measured directly by the axial strain of an optical fiber. According to previous experimental studies by several researchers [17-23], it has been demonstrated that the shift of the Bragg wavelength has a linear relationship to the applied strain in the axial direction. FBG sensors are highly attractive because of the inherent wavelength response and multiplexing capability in a distributive sensing network. In contrast to conventional strain resistance gauges, these sensors have immunity from electromagnetic interference. They are small and lightweight. They also have high temperature and radiation tolerance. Practically, they are flexible, stable and durable in harsh environments. In addition, FBG sensors are absolute and linear in response, as well as being interrupt immune and characterized by a low insertion loss. Thus, they can be multiplexed in a series of arrays along a single optical fiber. Furthermore, FBG sensors have been developed for a quasi-distributed or multi-point strain monitoring system in both surface-mounted and embedded sensing applications.

However, since only one sensing parameter, wavelength shift, is required in the sensor application, temperature and strain cannot be measured simultaneously with one single grating. To separate the strain signal from the temperature signal, different compensation methods of temperature effects have been reported in the literature [17-23]. In addition, discriminating techniques have been proposed in recent years, such as using the first-order or second-order diffraction forms to measure temperature and strain simultaneously [18], or using a chirped fiber grating written in a tapered 


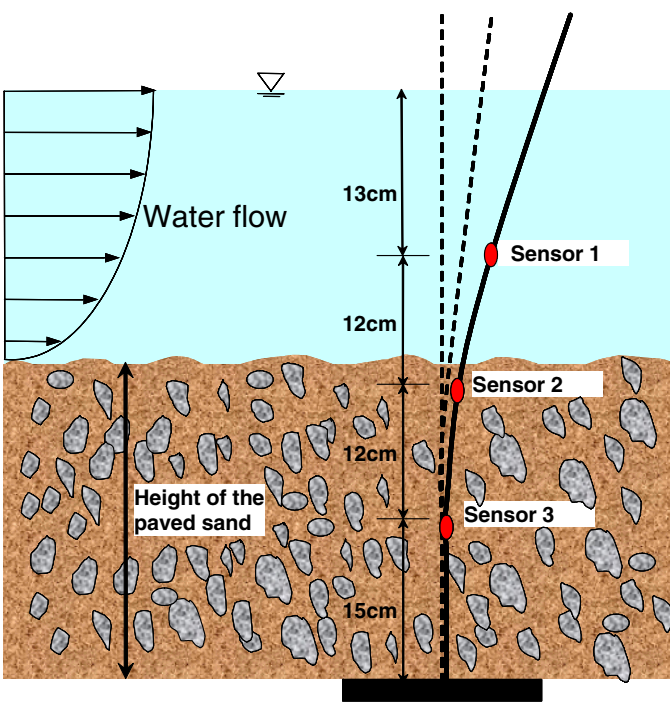

Figure 1. The FBG scour monitoring system-model I.

fiber to fabricate a temperature-independent FBG strain sensor [19]. Practically, with a matrix inversion technique, most of the applications utilize two superimposed FBGs written at two different wavelengths to decouple strain and temperature [20-23].

\section{Experimental setup and results}

\subsection{Experimental setup}

Two types of local scour monitoring systems are developed in the present study. As shown in figure 1, the FBG monitoring system of model I uses the cantilever mechanism to measure the local scour depth due to the variations of flow and bed level. Three FBG sensors, each sensor built with a desired wavelength, are mounted on the surface of a cantilevered beam and arranged in series along one single optical fiber. These three sensors, namely sensors 1, 2 and 3, are individually mounted at 15, 27 and $39 \mathrm{~cm}$ away from the bottom of the cantilevered beam partial submerged with a water level of $53 \mathrm{~cm}$ for each experiment. The experiments were conducted in a $12 \mathrm{~m}$-long, $0.3 \mathrm{~m}$-wide and $0.6 \mathrm{~m}$-deep flume with glass sidewalls at the Hydrotech Research Institute of National Taiwan University, Taipei, Taiwan. The cantilevered beam was placed in the middle of the flume paved by sand with various bed elevations of $0.33,0.30$ and $0.18 \mathrm{~m}$ for cases $1-3$, respectively. The prescribed discharge and its corresponding depth for each experimental case were controlled by adjusting the inlet valve and tailgate. As presented in figure 2 for model II, the FBG sensors illustrated by rectangular boxes are also arranged in series along one single optical fiber, but each FBG sensor is mounted on the cantilevered plate like a flag installed at a different level inside a hollow chamber of a steel pile fixed to the pier or the abutment. To simulate scouring/deposition of the river bed, a dune-like bed formation is assumed in the experimental setup. There are three runs, namely cases 4-6, tested in model II.

It is noted that all the FBG sensors of model I and model II are carefully protected from any damage in the experiment.

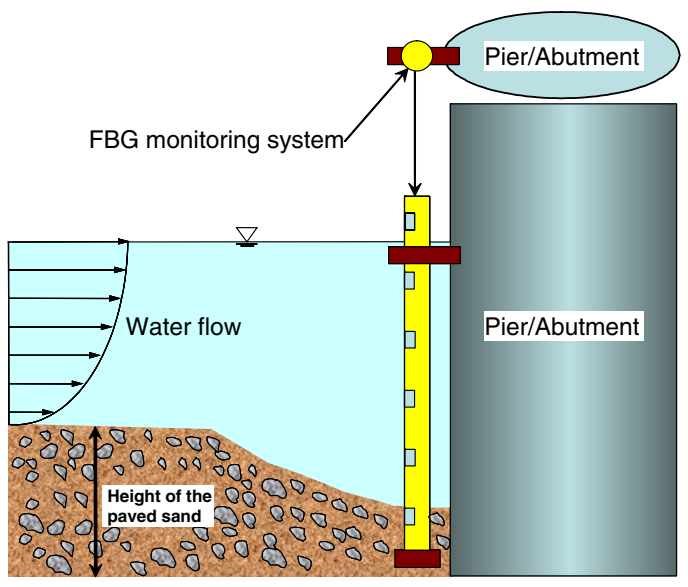

Figure 2. The FBG scour monitoring system-model II.

Table 1. Measured maximum strains $(\mu)$ for model I.

\begin{tabular}{lccc}
\hline & Case 1 & Case 2 & Case 3 \\
\hline Sensor 1 & 71 & 33 & 33 \\
Sensor 2 & 60 & 49 & 106 \\
Sensor 3 & 9 & 8 & 163 \\
\hline
\end{tabular}

Items measured include the water flow level, the scour depth and the riverbed elevation. When the running water flows towards the cantilevered device in model I or model II, a deformation strain will be generated by the bending moment, and this strain will be detected directly by the FBG sensor. If the FBG sensor is originally buried under the river bed surface, there is no response of the FBG sensor. The scour depth will be detected directly from the responses of the corresponding wavelengths, whenever the FBG sensor emerges from the river bed surface during scouring.

\subsection{Experimental results for model I}

From the experimental results of model I in figures 3-5, the local scour depth can be observed directly from the maximum strain of its corresponding FBG sensor. As presented in figure 3 and table 1 for case 1 , sensor 1 has the largest bending moment strain among the FBG sensors, since only sensor 1 emerges from the bed surface. It is obvious that the scour depth is the greatest at the location of sensor 1 . Due to the running water keeping eroding the sand bed, then sensor 2 emerges and the strain value increases as time elapses. As listed in table 1, the readings of the maximum strains in case 1 for sensors 1 and 2 are 71 and 60, respectively. However, sensor 3 does not emerge from the bed surface of the sediment deposits, and it only takes readings due to temperature. Note that the response of the scour depth is instantaneously monitored by the FBG sensors. During the experiment, sine-wave-like noises are detected and possibly induced by the vibration of the cantilevered beam. This vibration may be correlated with the motions of sediments and flows, which is attributed to the presence of transported sediment particles and fluid turbulence, especially at the emerging stage of the sensor. Similarly, as illustrated in figure 4 for case 2, sensor 3 does not emerge from 


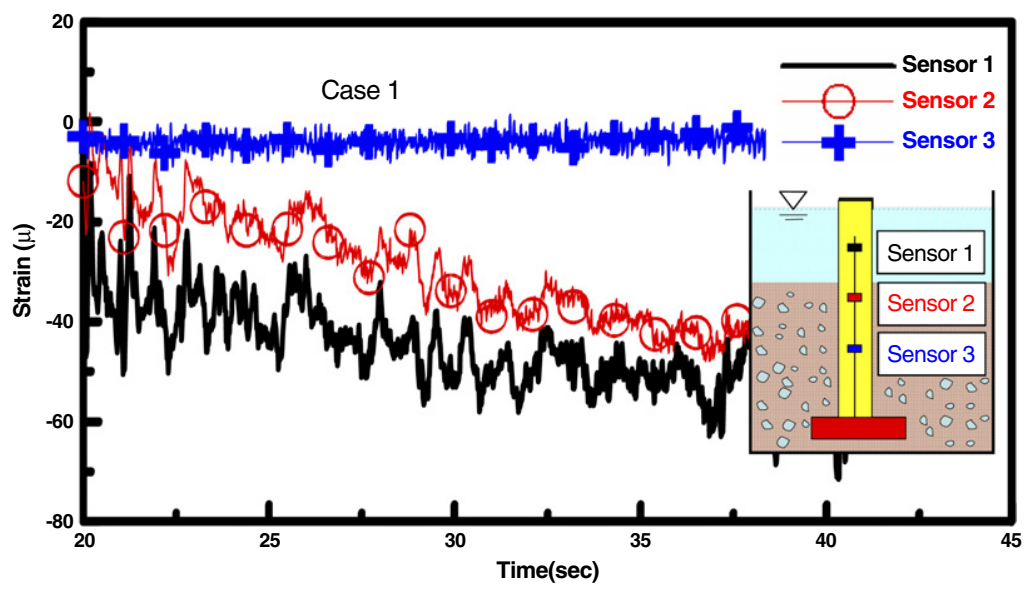

Figure 3. Experimental results of case 1 using model I.

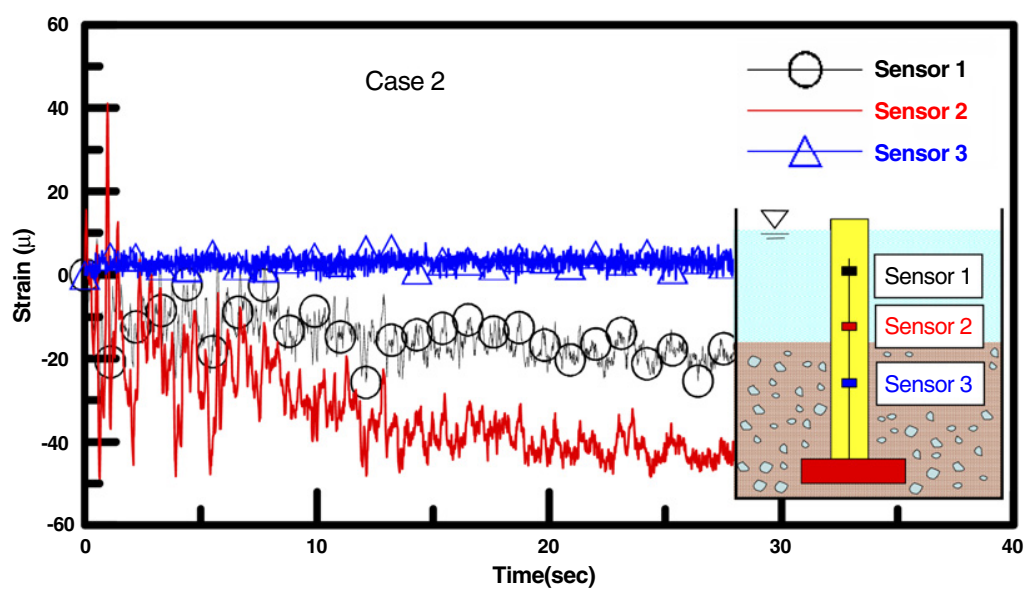

Figure 4. Experimental results of case 2 using model I.

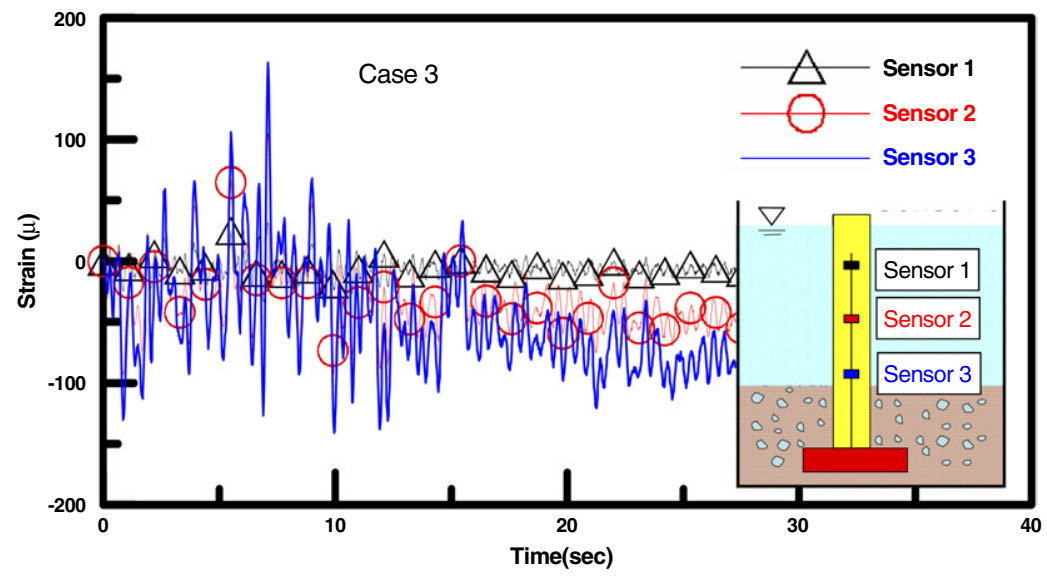

Figure 5. Experimental results of case 3 using model I.

the bed surface and it can only read some strain measurement due to temperature. Accordingly, for case 3 in figure 5, all of the sensors are submerged in the water at the initial setup of the experiment, and the maximum response of the strain reading obtained from sensor 3 is listed in table 1 .

\subsection{Experimental results for model II}

In model II, the initial experimental setup for cases 4-6 is illustrated in figure 6 . With the angle of repose, the dune-like bed formation paved by sand has a height of $0.5 \mathrm{~m}$. The scour 


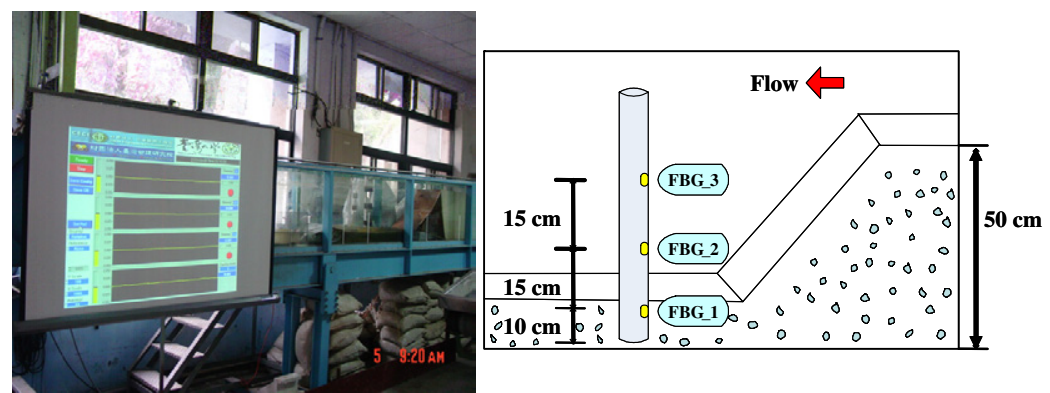

Figure 6. The experimental setup of model II.

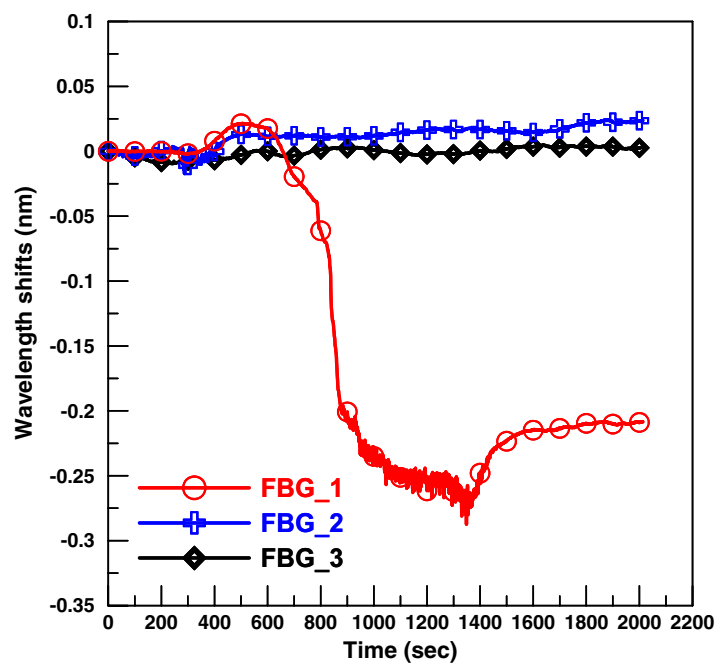

Figure 7. Experimental results of case 4 using model II.

monitoring system model II with three FBG sensors, namely FBG_1, FBG_2 and FBG_3, is placed $0.5 \mathrm{~m}$ away from the toe of the slope to measure water and bed levels variations. As case 4 starts, the given constant discharge is released at the upstream end of the experimental reach. When the running water arrives and makes contact with the cantilevered plate at 300 s, sensor FBG_1 responds first to the water temperature, as shown in figure 7. The change of water temperature is measured as a $0.025 \mathrm{~nm}$ wavelength shift, which corresponds to about $2{ }^{\circ} \mathrm{C}$ difference from the ambient air temperature [2]. The readings of the wavelength then shift when the water level keeps rising, and the flow is acting on the cantilevered plate of FBG_1 to generate a bending strain. The level of the running water can be obtained directly from the wavelength shifts of sensor FBG_1, as shown in figure 7. When FBG_1 emerges from the bed surface, it is obvious that the readings of the wavelength shifts change significantly as the flow velocity increases. After $1600 \mathrm{~s}$, the reading of FBG_1 is approximately constant because the water level remains constant at about $0.23 \mathrm{~m}$. Accordingly, the variations of the readings may be attributed to the presence of sediment particle motion and fluid turbulence induced by the flow velocity field. Sensor FBG_2 is affected in a minor way by the spattering water, while the water level does not reach FBG_3. On the other hand, the effects of the water level rising are investigated in case 5 with the same initial experimental setup as case 4 . Figure 8 presents

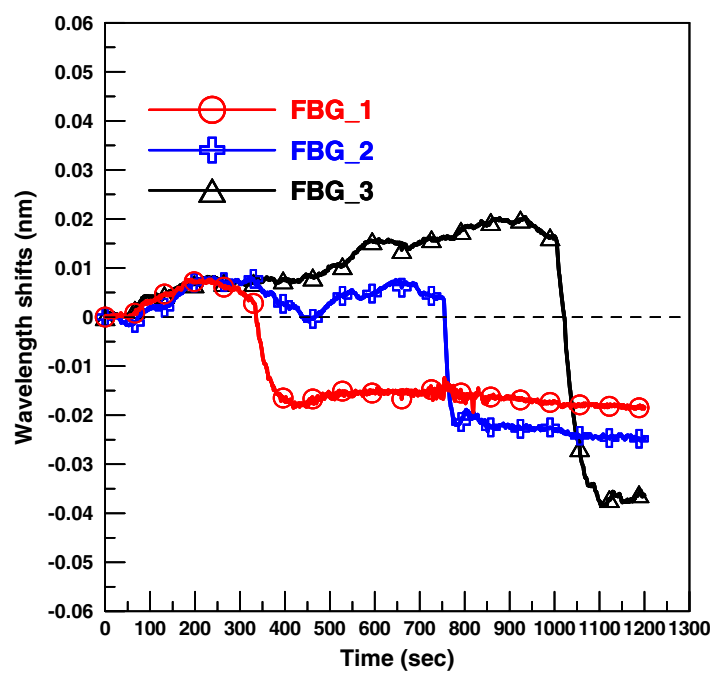

Figure 8. Experimental results of case 5 using model II.

the corresponding responds of three FBG sensors when the water level reaches each sensor at different elevations. From the above-mentioned results, it can be seen that not only the water level change is monitored in real time but also the flow velocity is detected. These results regarding acting strains correlate with the fluctuating flow-velocity field. Thus, the FBG sensor system can be useful for real-time measurements of water level and velocity in a flood.

To investigate the processes of scouring and deposition on the river bed, the experimental test of case 6 is introduced herein. For case 6, also conducted with the same initial experimental setup as case 4 , the experiment starts by releasing the given discharge upstream. Since the running water reaches the sensor FBG_1, it is affected immediately by the temperature of the water as mentioned earlier. The response to the change of water temperature shifts the wavelength of the FBG sensor approximately $0.02 \mathrm{~nm}$, which corresponds to $1-2{ }^{\circ} \mathrm{C}$, as shown in figure 9 at the beginning of the T1 stage. As the water level rises gradually and impacts upon the FBG sensor, the bending moment of the cantilevered plate is induced by the flow velocity, and it indicates the height of the water level as shown in figure 9 . Before the end of the $\mathrm{T} 1$ stage, the reading of strain decreases because the bed level is somehow refilled by the sediment transported from the dune-like formation. To mimic the deposition processes, fine sand is poured directly near the water surface of the sloping bed region at $150 \mathrm{~s}$. 


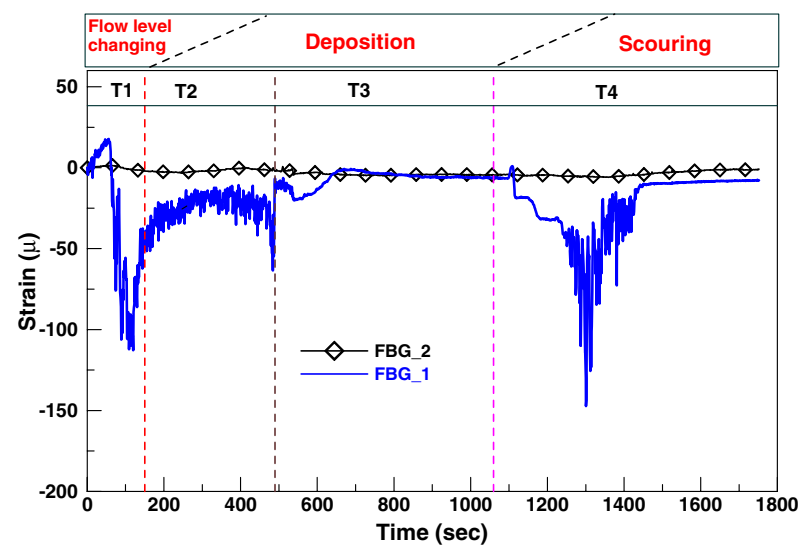

Figure 9. Experimental results of case 6 using model II.

Meanwhile, noise-like signals may be induced by sediment particle movement and flow turbulence, as mentioned in case 4 . In the period of the $\mathrm{T} 2$ stage, it is also observed that fluctuations resulting from flow and sediment movement increase with the responses of the wavelength shifts as the bed level rises due to deposition. With sand continuously being poured into the experimental reach, the cantilevered plate becomes buried. As shown at the T3 stage in figure 9, there is no reading of strain due to no external force acting on the plate after $700 \mathrm{~s}$, which indicates that the sensor is buried by sand. At $900 \mathrm{~s}$, sand feeding ceases and running water keeps eroding. After $1100 \mathrm{~s}$ at the T4 stage, as illustrated in figure 9 the FBG_1 sensor emerges again by the running water under scouring processes. The readings of the strain resume, and the scouring process is similar to that at the T1 stage. Since the cantilevered plate emerges from the deposited sediment, it reveals the scouring depth from the reading of strain. Apparently, the FBG sensor system is capable of measuring the water level, scour depth and deposition height as analyzed in the above.

\section{Summary and conclusions}

Scouring at a bridge pier in a river can be caused by general scour, contraction scour or local scour. Among them, local scour is the most critical, and it is generally caused by the interference of the structures with river flow, which is one of the major causes for bridge failure. Without prior warning or sign of distress to the structures, scour failure tends to occur suddenly. A great deal of effort has been dedicated to the development and evaluation of scour detection and instrumentation in order to obtain more accurate measurements. Essentially, it is important to measure or monitor the depth variations of scouring at piers in a flood.

Two types of the real-time scour monitoring systems, namely model I and model II, using fiber Bragg grating (FBG) sensors, have been developed and tested in the laboratory. These novel FBG scour-monitoring systems can measure both the processes of scouring/deposition and the variations of water level. Six experimental runs were conducted in the flume to demonstrate the applicability of the FBG systems. In model I, the FBG sensors built with a desired wavelength are mounted on the surface of a cantilevered beam and arranged in series along a single optical fiber. In model II, the FBG sensors are also arranged in series along a single optical fiber, but each FBG sensor is mounted on the cantilevered plate like a flag installed at different level inside a hollow chamber of a steel pile fixed to the bridge pier. The FBG sensors apply the cantilever mechanism to measure the corresponding strains. From the experimental results, such FBG sensor systems can be useful for real-time measurements in a flood.

In the present study, it is shown that the FBG systems have demonstrated the capability to measure the water level, scour depth and deposition height. The experimental results indicate that a real-time monitoring system using FBG sensors has the potential for further applications to bridge scour in the field. However, to protect it from being damaged by the huge impact forces of a high-velocity flood with drifting debris and sediments, the installation procedures as well as the packaging of the FBG scour monitoring system require careful designs for practical engineering purposes.

\section{Acknowledgments}

The authors gratefully acknowledge the Directorate General of Highways, Ministry of Transportation and Communications, ROC, China Engineering Consultants, Inc., and the Hydrotech Research Institute, National Taiwan University, Taipei, Taiwan, for partial support during the last two years. The authors would like to thank Mr L S Lee, and Mr S H Wu, National Center for Research on Earthquake Engineering, for their kind help in data collection.

\section{References}

[1] Shirole A M and Holt R C 1991 Planning for a comprehensive bridge safety assurance program Transp. Res. Rec. 1290 Transportation Research Board, Washington, DC, pp $137-42$

[2] Lin Y B, Lin T K, Kuo Y H, Wang L A and Chang K C 2002 Application of FBG sensors to strain and temperature monitoring of full scale prestressed concrete bridges $O F S$ 2002: Optical Fiber Sensors 15th Int. Conf. Technical Digest pp 211-4

[3] Cuevas K J, Buchanan M V and Moss D 2002 Utilizing side scan sonar as an artificial reef management tool Oceans'02 $M T S / I E E E$ vol 1, pp 136-40

[4] De Falco F and Mele R 2002 The monitoring of bridges for scour by sonar and sedimetri NDT\&E Int. 35 117-23

[5] Mason R R and Shepard D M 1994 Field performance of an acoustic scour-depth monitoring system Proc. Fundamentals and Advancements in Hydr. Measurements and Experimentation, ASCE pp 366-75

[6] Davidson N C, Hardy M S A and Forde M C 1995 Bridge scour assessment by impulse radar Radar and Microwave Techniques for Non-Destructive Evaluation 8/1-8

[7] Hayes D C and Drummind F E 1995 Use of fathometers and electrical-conductivity probes to monitor riverbed scour at bridges and piers Water Resour. Investigations Rep. No. 88-4212 US Geological Survey, Hartford.

[8] Dowding C H and Pierce C E 1994 Use of time domain reflectometer to detect bridge scour and monitor pier movement Proc. Symp. and Workshop on Time Domain Reflectometry in Envir., Infrastruct. and Mining Application pp 579-87

[9] Yankielun N E and Zabilansky L 1999 Laboratory investigation of time-domain reflectometry system for monitoring bridge scour J. Hydraul. Eng. 125 1279-84 
[10] Lagasse P F, Richardson E V, Shall J D and Price G R 1997 Instrumentation measuring scour at bridge piers and abutments NCHRP Rep. 396 Washington, DC

[11] Baglio S, Faraci C, Foti E and Musumeci R 2000 Stereo vision for noninvasive dynamic measurements of the scour process around a circular cylinder in an oscillating flow OCEANS 2000 MTS/IEEE Conf. and Exhibition vol 2, pp 987-92

[12] Babu M R, Sundar V and Rao S N 2003 Measurement of scour in cohesive soils around a vertical pile-simplified instrumentation and regression analysis IEEE J. Ocean. Eng. 28 106-16

[13] Baglio S and Foti E 2003 Non-invasive measurements to analyze sandy bed evolution under sea waves action IEEE Trans. Instrum. Meas. 52 762-70

[14] DeVault J E 2000 Robotic system for underwater inspection of bridge piers IEEE Instrum. Meas. Mag. 3 32-7

[15] Judge J and Forbes D 1987 Measurements of currents, bottom sediments and seafloor disturbance CASP OCEANS 19 975-80

[16] Chang W Y, Lai J S and Yen C L 2004 Evolution of scour depth at circular bridge pier nose J. Hydraul. Eng. ASCE 130 905-13

[17] Chang K C, Chern J C, Wang L A, Lin Y B and

Chen H L 1998 A study of fiber Bragg grating sensors in civil structures J. Chin. Inst. Civil Hydraul. Eng. 10 467-75
[18] Kalli K, Brady G P, Webb D J, Jackson D A, Reekie L and Archambault J L 1995 Possible approach for the simultaneous measurement of temperature and strain via first- and second-order diffraction from Bragg grating sensors Proc. SPIE: Distributed and Multiplexed Fiber Optic Sensors V vol 2507, pp 190-8

[19] Xu M G, Dong L, Reekie L, Tucknott J A and Cruz J L 1995 Temperature-independent strain sensor using a chirped Bragg grating in a tapered optical fiber Electron. Lett. 31 $1085-8$

[20] Miridonov S V, Shlyagin M G and Tentori-Santa-Cruz D 1999 Digital demodulation of a twin-grating fiber optic sensor Proc. SPIE in Fiber Optic and Laser Sensors and Applications; Including Distributed and Multiplexed Fiber Optic Sensors VII vol 3541, pp 33-40

[21] Lin Y B, Chang K C, Chern J C and Wang L A 2004 The health monitoring of a prestressed concrete beam by using fiber Bragg grating sensors Smart Mater. Struct. 13 712-8

[22] Lin Y B, Chang K C, Chern J C, Chan Y W and Wang L A 2004 The utilization of fiber Bragg grating sensors to monitor high performance concrete at elevated temperature Smart Mater. Struct. 13 784-90

[23] Rao Y J, Lobo Ribeiro A B, Jackson D A, Zhang L and Bennion I 1996 Simultaneously spatial-, time-, and wavelength-division multiplexed in-fiber Bragg grating sensor network Proc. SPIE in Distributed and Multiplexed Fiber Optic Sensors VI vol 2838, pp 23-30 